\title{
Factors controlling elastic properties in carbonate sediments and rocks
}

\author{
Gregor P. EBerLI and Gregor T. BAECHLE, University of Miami, Florida, U.S. \\ Flavio S. Anselmetti, Swiss Federal Institute of Technology, Zurich, Switzerland \\ MICHAEL L. INCZE, DIVNPT, Naval Undersea Warefare Center, Newport, Rhode Island, U.S.
}

$\mathrm{C}_{\mathrm{a}}$ diagenetic alterations that change the mineralogy and pore structure within carbonate rocks. In particular, cementation and dissolution processes continuously modify the pore structure to create or destroy porosity. In extreme cases these modifications can completely change the mineralogy from aragonite/calcite to dolomite, or reverse the pore distribution whereby original grains are dissolved to produce pores as the original pore space is filled with cement to form the rock (Figure 1). All these modifications alter the elastic properties of the rock and, therefore, the sonic velocity. The result is a dynamic relationship among diagenesis, porosity, poretype, and sonic velocity. The result is a wide range of sonic velocity in carbonates, in which compressional-wave velocity $\left(V_{P}\right)$ ranges from 1700 to $6600 \mathrm{~m} / \mathrm{s}$ and shear-wave velocity $\left(V_{S}\right)$ from 600 to $3500 \mathrm{~m} / \mathrm{s}$.

Porosity is the main controlling factor in determining the sonic velocity in rocks but in carbonates the pore type is nearly equally important in the elastic behavior and resultant sonic velocity (Anselmetti and Eberli, 1993, 1997). Most of the current theoretical equations do not, or insufficiently, account for this modification of the elastic behavior by the pore type. Consequently, seismic inversion, AVO analysis, and calculations of pore volumes that are based on these equations are prone to large uncertainties in carbonates.

We measured acoustic velocities on modern carbonate sediments and rocks in various stages of diagenesis to reveal the relationships between original composition, porosity, pore type, and velocity. The apparatus for these laboratory experiments, constructed by VerdeGeoScience, consists of an oil-filled pressure vessel that contains the ultrasonic transmitter-receiver pair with piezoelectric transducers and the sample. Miniplug samples of one inch $(2.5 \mathrm{~cm})$ diameter and 1-2 inches in length are positioned between two piezoelectric transducers and sealed from the confining oil in the pressure vessel. Confining and pore-fluid pressures are chosen independently to simulate most accurately insitu stress conditions of buried rocks. The pore-fluid pressure is kept stable at $2 \mathrm{MPa}$ and the confining pressure is varied between 3 and $100 \mathrm{MPa}$, resulting in an effective pressure of up to $98 \mathrm{MPa}$. The pair of transducers generates one compressional wave signal $\left(V_{P}\right)$ and two perpendicularly polarized shear wave signals $\left(V_{S} 1, V_{S} 2\right)$ at central frequencies close to $1 \mathrm{MHz}$.

Sonic velocity of carbonate sediment. Grain size and shape, sorting, and the ratio between grain and matrix influence acoustic velocity in unconsolidated carbonate sediment. Pure carbonate mud has an average porosity of $60 \%$ and $V_{P}$ of $\sim 1700 \mathrm{~m} / \mathrm{s}$. At a compression of $170 \mathrm{MPa}$, the porosity is reduced to $29 \%$ and $V_{P}$ increases to $2250 \mathrm{~m} / \mathrm{s}$, while $V_{S}$ is between $900-1200 \mathrm{~m} / \mathrm{s}$. These mud samples have a low shear modulus and, thus, a behavior similar to materials that have no rigidity (liquids). Carbonate sand (ooids and skeletal grains) show relatively consistent $V_{P}$ values ranging from 2100 to $2400 \mathrm{~m} / \mathrm{s}$ at confining pressures of $10 \mathrm{MPa}$ and an increase to 3500-3700 at $80 \mathrm{MPa}$. These two endmembers

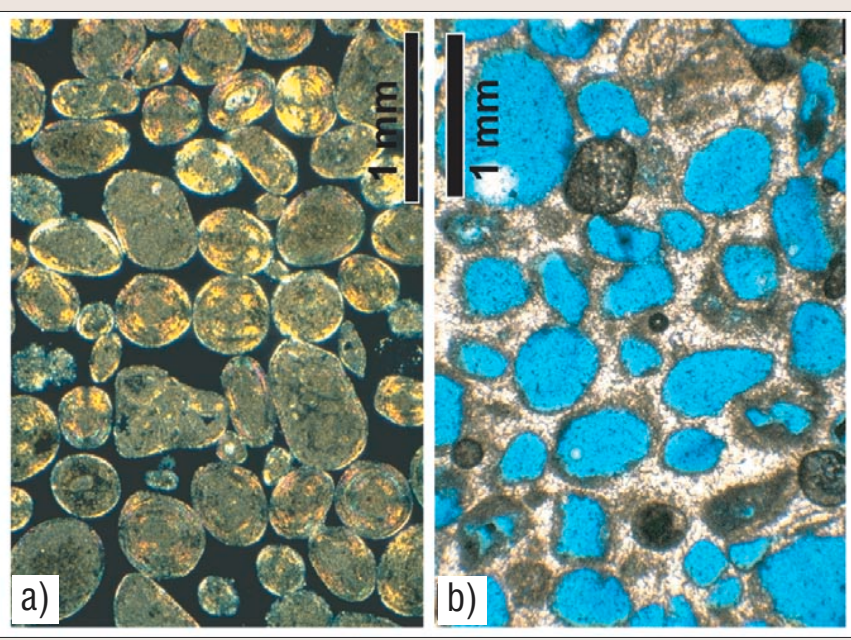

Figure 1. Illustration of pore type transformation from interparticle to moldic during diagenesis. (a) Photomicrograph of oolithic carbonate sand with interparticle pore space is in black. (b) Photomicrograph of moldic carbonate rock. The molds (blue epoxy) are created by the dissolution of ooids and peloids whereas the former pore space is filled with blocky white cement to form the rock.

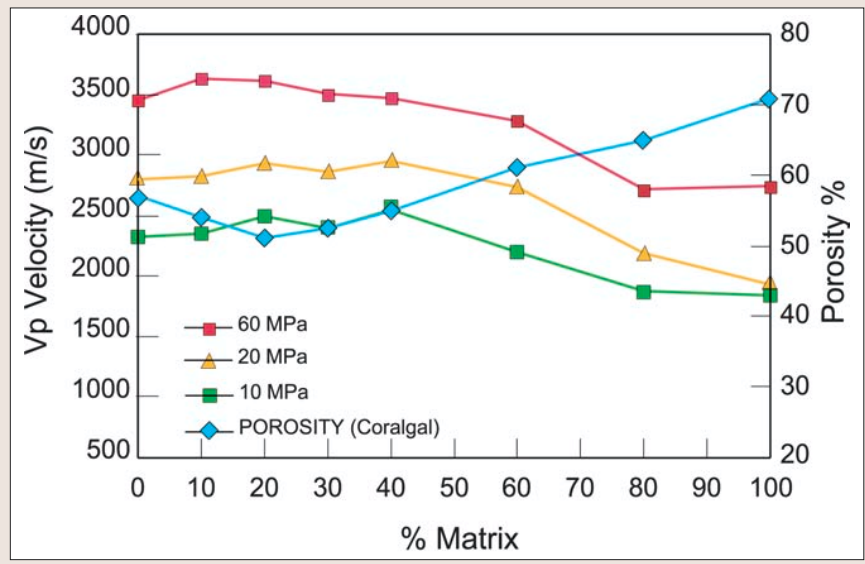

Figure 2. Matrix versus velocity and porosity of mud/grain mixtures. Mud is the matrix. Porosity initially decreases with the addition of matrix but increases after $20 \%$ mud is added. Velocity reacts inversely and increases initially before decreasing in samples with more than $40 \%$ mud.

(mud and grain) mix to produce a wide variety of carbonate sediment. Their relative amount is used to classify carbonate rocks from mudstone ( $<10 \%$ grain), wackestone (>10\% grain), packstone (grain supported), and grainstone (no mud). We conducted a series of experiments to assess the effect of the matrix/grain ratio on velocities under various pressures in a similar way as was done for sand and clay mixtures in clastics (Marion et al., 1992). Two types of grains, round ooid grains of $0.375 \mathrm{~mm}$, and skeletal grains (platy coralgal) of $0.500 \mathrm{~mm}$, were used in this experiment, while the fine fraction was lagoonal mud of less than 64 microns in diameter. The fine fraction was added at $10 \%$ (weight) increments to produce samples from pure carbonate sand to pure carbonate mud. Porosity initially decreases 


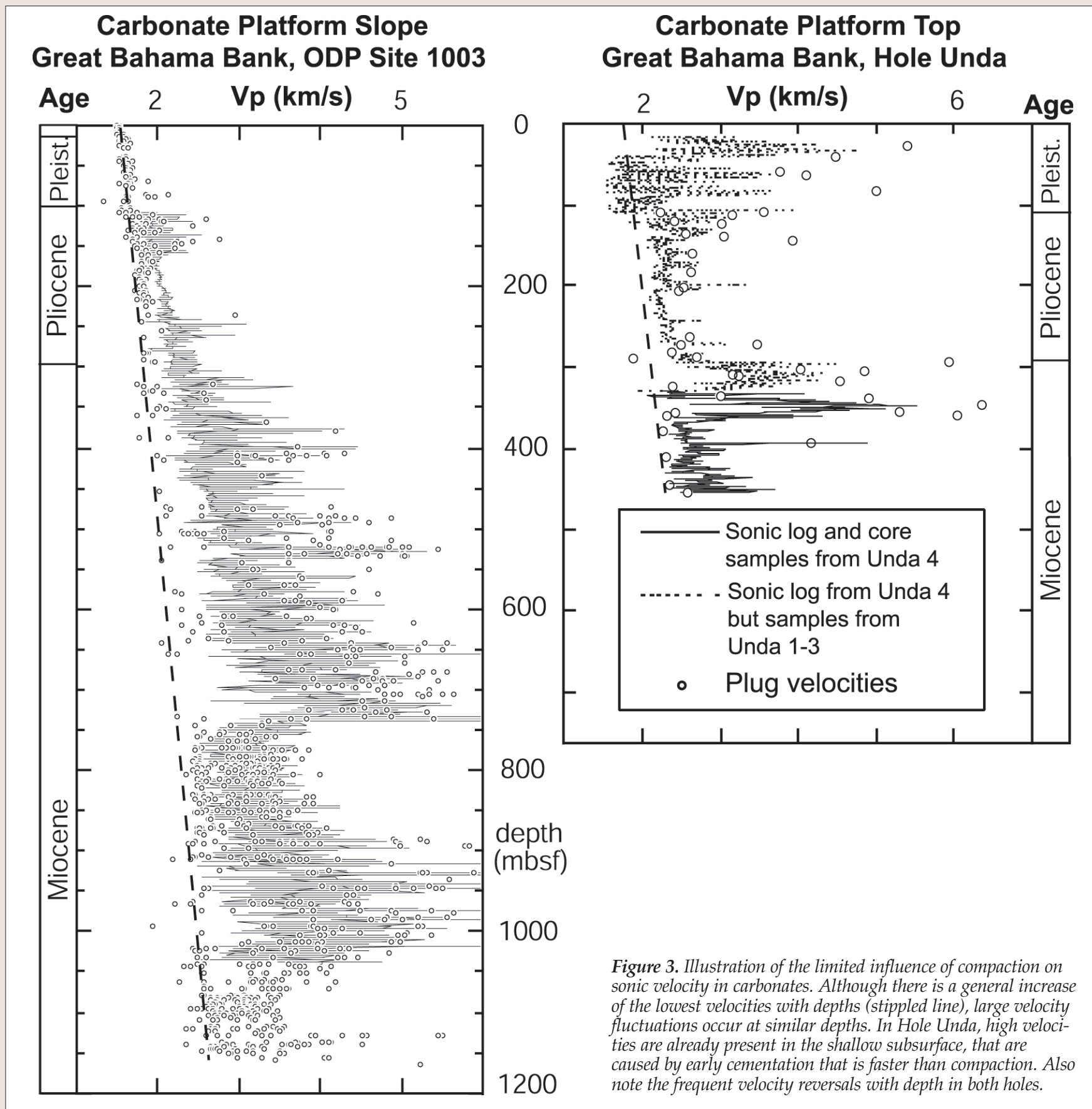

with the addition of mud to a critical point before the trend reverses. This point occurs at $10 \%$ in the ooid grain mixture and at $20 \%$ in the skeletal grain mixture. With additional matrix, the porosity increases again and converges to the natural porosity of the matrix material (Figure 2). Initial increases of matrix (0-20\%) cause an increase in acoustic velocities at all confining pressures, concurrent with decreasing porosity. A reversal of the trend occurs with the continued addition of fine-grained matrix. For the ooid grain mixture, velocity starts to decrease at $40 \%$ matrix, while in the skeletal grain mixture more than $50 \%$ of matrix is needed to decrease the velocity at all confining pressures. The differences between the two data sets indicate that grain shape and grain-to-matrix diameter are important for the change in poroelastic properties and the critical porosity in carbonate sediment.
The influence of compaction and early cementation on velocity. In siliciclastic sediments, compaction from overburden pressure is an important process to reduce porosity and increase velocity. Carbonates are highly susceptible to other diagenetic changes, which can occur more quickly than compaction. Thus, in carbonates compaction, burial depth or age is less important for velocity. Velocity is controlled by the combined effect of depositional lithology and several postdepositional processes that cause a special velocity distribution in carbonates. Early compaction of the sediment, by which we mean the process of initial consolidation, dewatering, and pore space reduction (but no cracking or breaking of the components) reduces initial values of approximately $60 \%$ porosity and $1600 \mathrm{~m} / \mathrm{s}$ of $V_{P}$ to values close to $40-50 \%$ and $2000 \mathrm{~m} / \mathrm{s}$.

In concert and often before compaction, cementation or dissolution processes occur in carbonate sediments. 


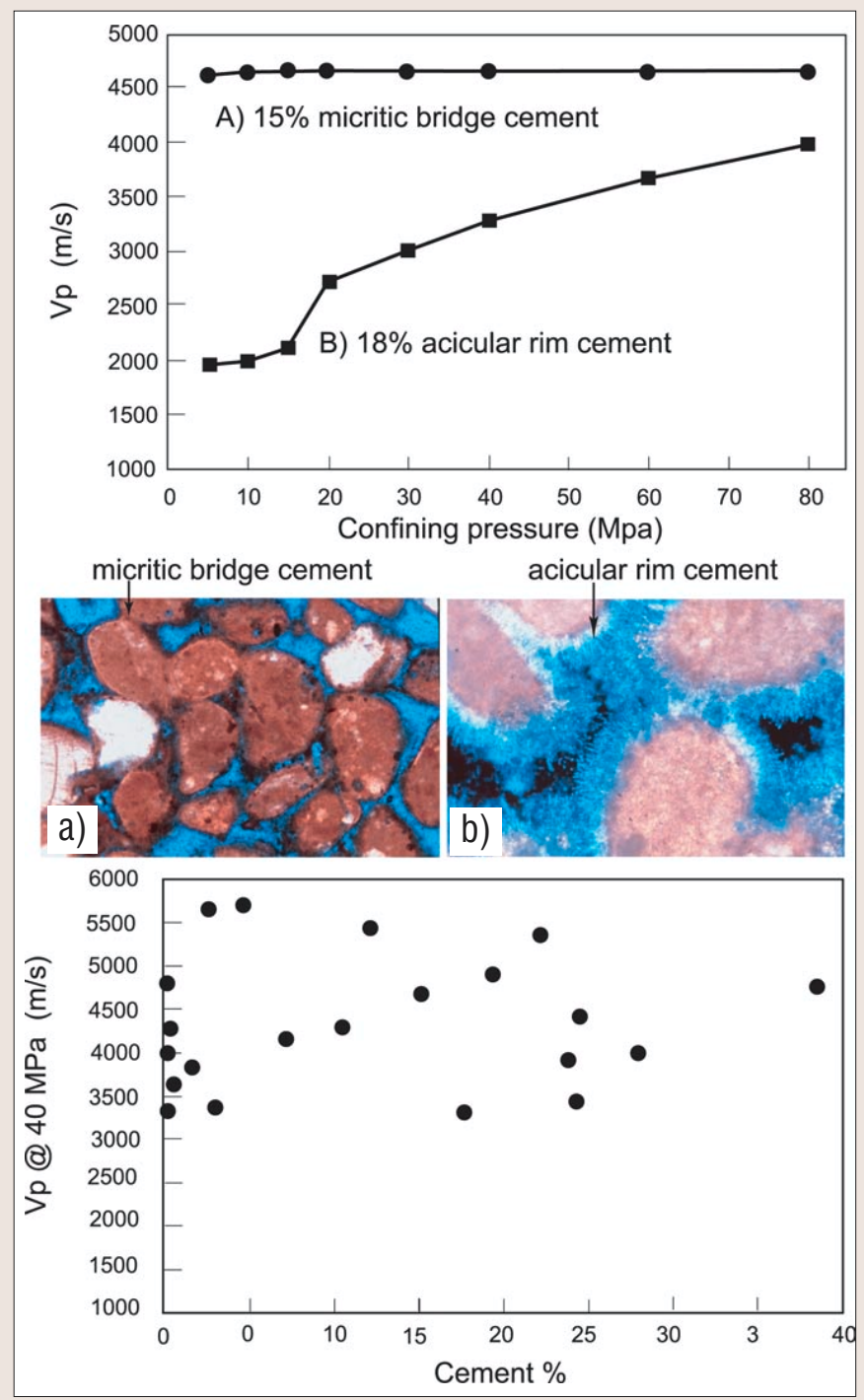

Figure 4. Velocity in rocks cemented by early marine cements display no correlation between amount of cement and velocity. The reason is the different forms of cement that change the rigidity with variable amounts. Micritic or sparitic cement at grain contacts is more efficient in building a rigid frame than is needle-like acicular cement.

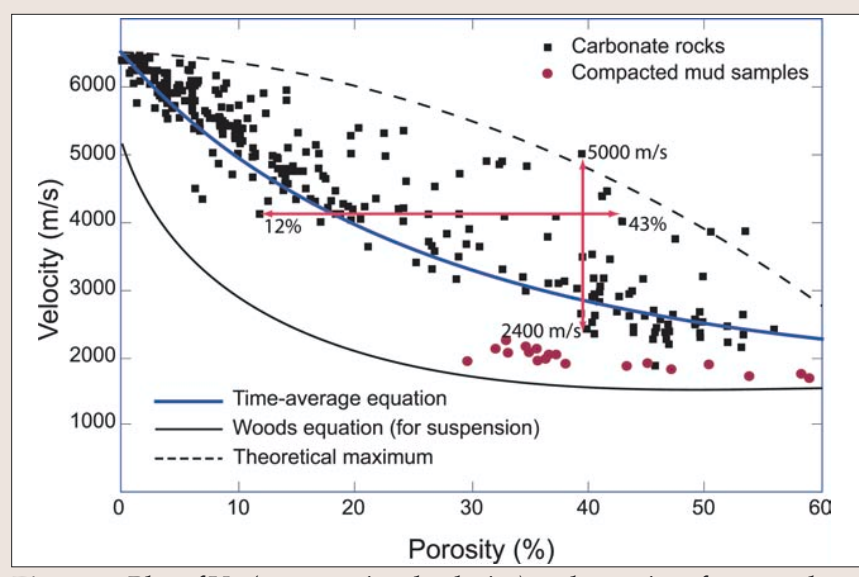

Figure 5. Plot of $\mathrm{V}_{\mathrm{P}}$ (compressional velocity) and porosity of pure carbonate samples compared to the time average and Woods equation. Velocities of compacted mud samples are only slightly higher than the Woods equation, indicating that these samples have nearly no rigidity and that compaction has a minor effect on $\mathrm{V}_{\mathrm{P}}$. The diagenetically altered carbonate samples show an inverse relationship between porosity and velocity but there is a large scattering of velocity values at equal porosities, and a large range of porosity at a given velocity. This scattering introduces uncertainty in seismic inversions.

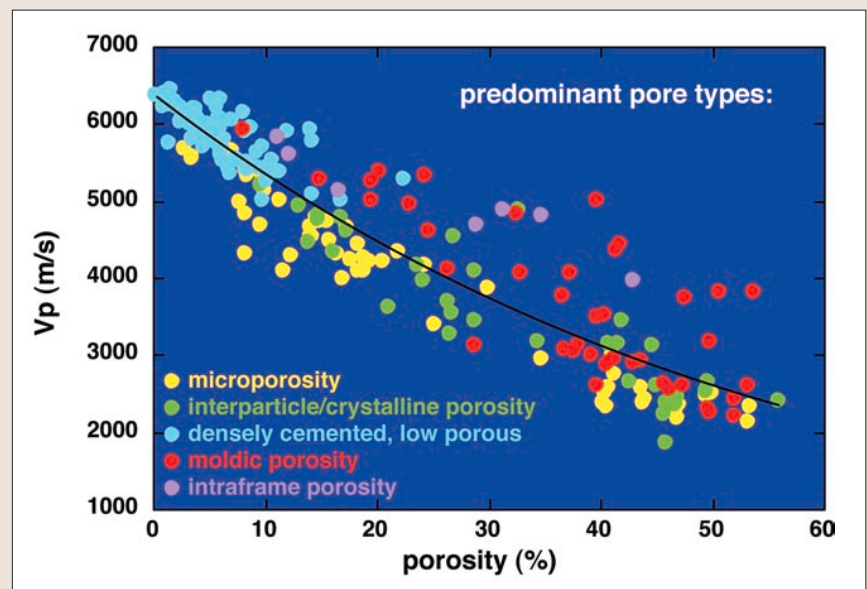

Figure 6. Graph of velocity (at $8 \mathrm{MPa}$ effective pressure) versus porosity of various pore types of carbonates with an exponential best fit curve through the data for reference. Different pore types cluster in the porosityvelocity field, indicating that scattering at equal porosity is caused by the specific pore type and their resultant elastic property.

Cementation can transform carbonate sediment within months into a rock. These shallow subsurface cementation processes add stiffness to the young rocks, which results in a significant increase in velocity that is much greater than the velocity increase due to compaction. Figure 3 illustrates this phenomenon with logs and velocity measurements on discrete samples from two holes located on modern Great Bahama Bank, where compaction is only caused by the sediment overburden pressure. Although there is a general trend of increasing velocity with depth, velocity inversions with depth are common and values of compressional wave velocities can vary up to $4000 \mathrm{~m} / \mathrm{s}$ at approximately the same depth. Furthermore, $V_{P}$ velocities of over $4000 \mathrm{~m} / \mathrm{s}$ are found in shallow burial depths of less than $20 \mathrm{~m}$ at the shallow-water site, Unda. At this location, frequent exposure and early marine cementation lithify the sediment prior to burial. Further downhole from 180-250 m below seafloor, the velocities decrease to approximately $2000 \mathrm{~m} / \mathrm{s}$ before jumping back to values of nearly $5000 \mathrm{~m} / \mathrm{s}$. Diagenesis is not as rapid in the deeper water and compaction is better recognized in a core from the slope of Great Bahama Bank that was retrieved in a water depth of $481 \mathrm{~m}$ (ODP Site 1003). In this hole, the $V_{P}$ velocities initially increase with depth in the unlithified portion of the core. With the onset of cementation, below a hundred meters, velocities start to spike in thin horizons, and at approximately $400 \mathrm{~m}$ below seafloor, velocity values range from $2000 \mathrm{~m} / \mathrm{s}$ to $4500 \mathrm{~m} / \mathrm{s}$. These large velocity ranges at any given depth document that compaction is no longer the dominant factor for velocity and that cementation and dissolution processes determine the elastic behavior of the rock.

In the transition from sediment to rock, the fusing of grains by cementation is the most important factor for changing the elastic behavior and thus velocity. In carbonates, a variety of cements occur depending on the chemistry and the fluid flow regime. Some cements form at the contact points of grains, "welding" the grains to a stiff framework. Others grow along the entire grain toward the interparticle pore space either as blocky calcite or as fine aragonite needles. Experiments show that the amount of these early cements do not correlate well with velocity but that the different cement types change the elastic property of the young rocks differently (Figure 4). For example, small amounts of bridging cement ( $15 \%$ of the total rock) at grain contacts stiffens a sediment dramatically to produce a $V_{P}$ of $4500 \mathrm{~m} / \mathrm{s}$. Acicular cement that binds the grains by interlocking of 

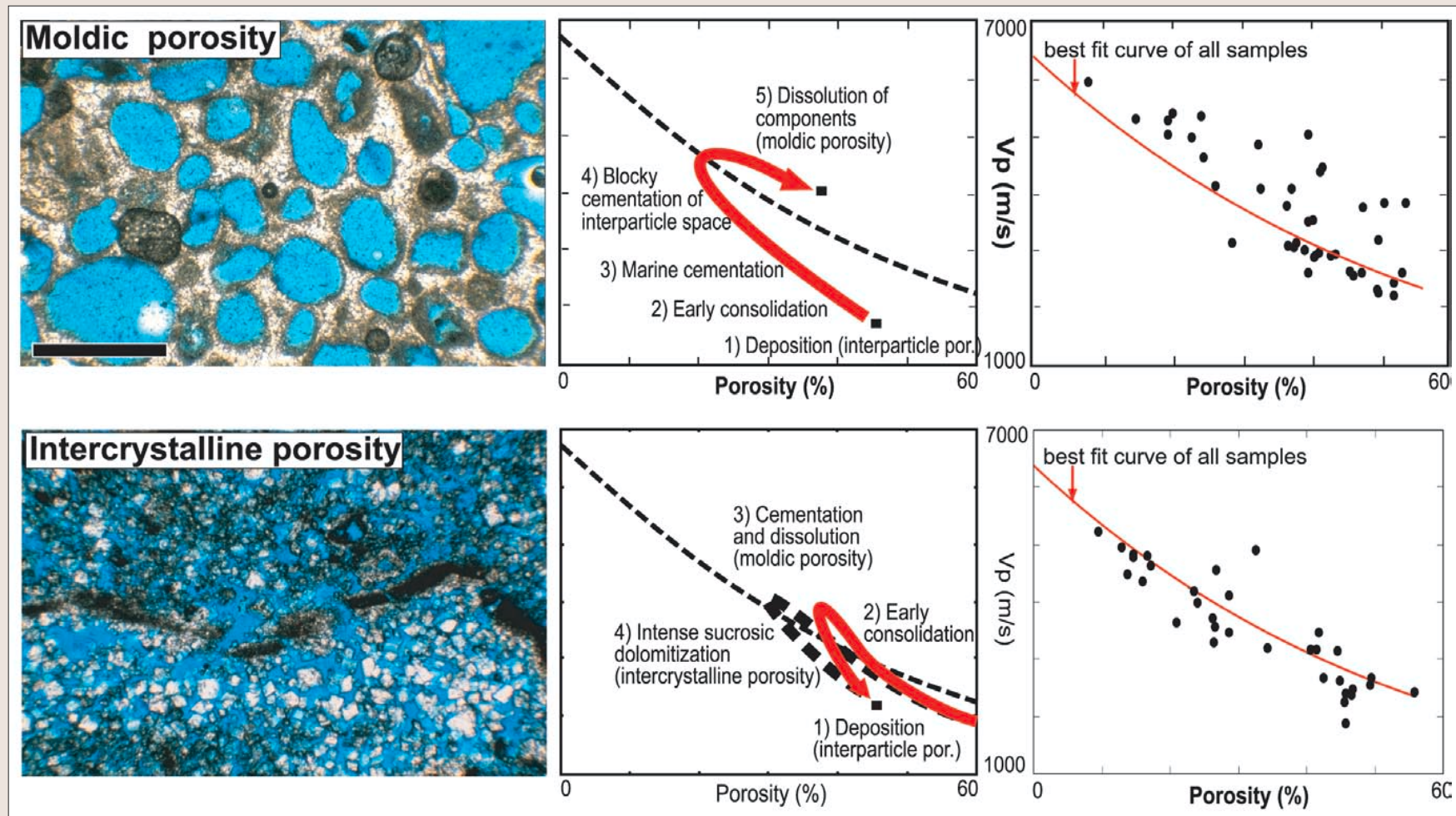

Figure 7. Examples of two dominant pore types with different elastic behavior. The moldic rocks are formed by the dissolution of grains, precipitation of cements that now form a stiff frame, which provides rigidity to the rock. As a result, moldic rocks have a high velocity compared to their porosity. In contrast, fabric destructive dolomitization produces a rock with intercrystalline porosity with low rigidity and low velocity.

crystals is less efficient in changing the elastic behavior of the rock. For example, $18 \%$ of acicular cement result in a rock with a velocity of approximately $2000 \mathrm{~m} / \mathrm{s}$ at $10 \mathrm{MPa}$. As diagenesis progresses these original differences diminish to certain extent. However, the ability of certain cements to stiffen the carbonate rocks without significantly reducing the pore space results in variations of velocity at any given porosity value.

Porosity and pore type. Velocity is strongly dependent on the rock-porosity (Wang et al., 1991; Rafavich et al., 1984). A plot of porosity versus velocity displays a clear inverse trend; an increase in porosity produces a decrease in velocity (Figure 5). The measured values, however, display a large scatter around this inverse correlation in the velocityporosity diagram. Velocity differences at equal porosities can be over $2500 \mathrm{~m} / \mathrm{s}$, in particular at higher porosities. For example, rocks with porosities of $39 \%$ can have velocities between $2400 \mathrm{~m} / \mathrm{s}$ and $5000 \mathrm{~m} / \mathrm{s}$. Even at porosities of less than $10 \%$ the velocity can still vary about $2000 \mathrm{~m} / \mathrm{s}$, which is an extraordinary range for rocks with the same chemical composition and the same amount of porosity. Likewise, porosity can vary widely at any given velocity. For example, rocks with a $V_{P}$ of $4100 \mathrm{~m} / \mathrm{s}$ can have porosities anywhere between $12 \%$ and $43 \%$. These ranges are of paramount importance for seismic inversion. Most techniques use either an equation or the best-fit curve through porosity/velocity data for seismic inversion. The large scattering will inadvertently result in large uncertainties in the inversion and calculations of porosity volumes. The weak relationship between porosity and velocity in carbonates is caused by the ability of carbonates to form cements and special fabrics with pore types that can enhance the elastic properties of the rock without filling all the pore space. The importance of the pore type on the elastic property and thus the veloc- ity is illustrated in Figure 6, which shows that the different pore types form clusters in the velocity-porosity diagram. This characteristic pattern for every group with the same dominant pore type can explain why rocks with equal porosity can have very different velocities. The samples can be grouped into five categories of pore types.

Interparticle and intercrystalline porosity. The pore space between grains (interparticle) and between crystals (intercrystalline) have similar petrophysical behavior. In both instances, the predominant fabric is an assemblage of components with little or no cement or matrix. This accumulation of loose grains / crystals results in a low velocity and a negative departure from the average correlation curve in the porosity-velocity diagram (Figure 7).

Microporosity. This type of porosity with micropores of approximately 10 micron has a similar effect on velocity like fine-grained, interparticle porosity, resulting in a lower velocity than the general trend.

Moldic porosity. Moldic porosity develops by dissolution of grains after or during cementation of the interparticle pore-space. Some rocks consist almost purely of a framework of cement around the molds (Figure 7). The resultant high elastic moduli result in velocities which are higher than velocities predicted by equations, such as the time average equation. Rocks with moldic porosity between 40 and $50 \%$ can have velocities between 4000 and $5000 \mathrm{~m} / \mathrm{s}$, which is extraordinary for such highly porous rocks. Velocities are higher in coarse-moldic rocks, whereas finemoldic samples are relatively slow and plot close to the time average equation in the velocity-porosity diagram.

Intraframe porosity in frame- or boundstones. Framestones and boundstones, formed by organisms such as corals or bryozoans, consist of a constructional framework with a porosity that is embedded in the solid frame. Therefore, these samples show a similar velocity-porosity pattern like 


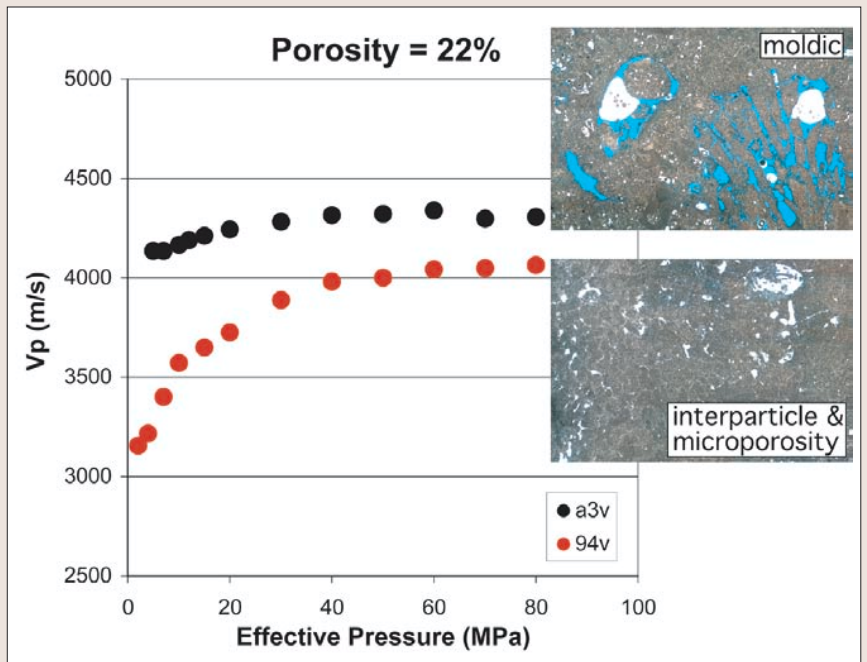

Figure 8 . Comparison of rocks with $22 \%$ porosity but different pore types. The sample with moldic porosity has a high initial $\mathrm{V}_{\mathrm{P}}$ velocity, which only slightly increases with additional pressure. In contrast the sample with interparticle and microporosity has a low initial $\mathrm{V}_{\mathrm{P}}$ velocity and a strong increase of velocity with increasing pressure without reaching the value of the moldic rock. The persistant difference of velocity indicates that differences in velocity due to pore type are maintained in the subsurface.
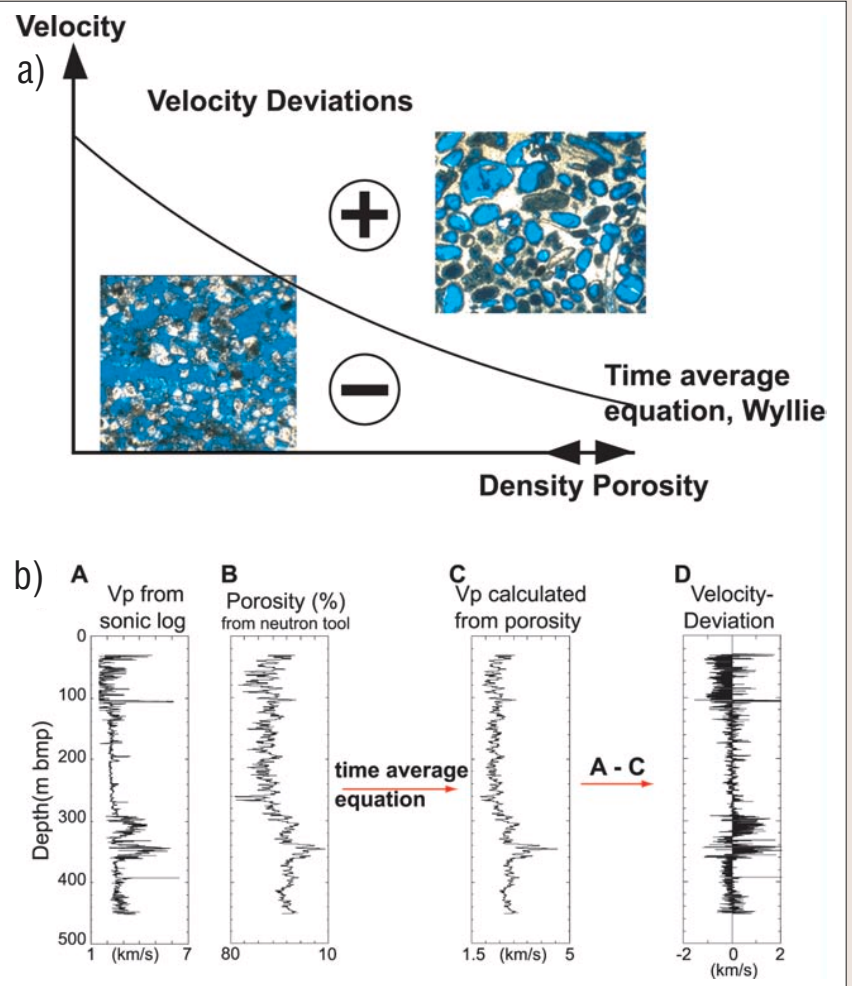

Figure 9. Principle and methodology for the velocity deviation log. (a) Taking velocities of the time-average equation as base line, pore types that are embedded in a stiff frame produce positive deviations, while interparticle/intercrystalline, and microporosity fall at or slightly below the line. (b) The velocity deviation is calculated by converting the neutron-porosity log (B) into a synthetic sonic $\log (C)$. The difference between the measured sonic $\log (A)$ and the synthetic sonic $\log (C)$ defines the velocity deviation $\log$. The velocity deviation $\log (D)$ is plotted as positive and negative fill around the zero-deviation line.

the coarse moldic porous rocks that also have a frame with high elastic rigidity and a positive deviation from the general trend in the velocity-porosity diagram.

Low-porosity carbonates. These samples show an intense cementation of the pore-space and have porosities of $20 \%$ or less. Velocities are high, around $6000 \mathrm{~m} / \mathrm{s}$ for $V_{p}$, and close to the values of the minerals calcite $(6500 \mathrm{~m} / \mathrm{s})$ and dolomite $(7300 \mathrm{~m} / \mathrm{s})$.

These different porosity-velocity relations of carbonates clearly document that it is not only the porosity amount which determines velocity but also the porosity type. The most prominent velocity contrasts at equal porosities are measured between coarse moldic rocks and rocks with interparticle porosity. Moldic rocks at $40-50 \%$ porosity can have $V_{P}$ up to $5000 \mathrm{~m} / \mathrm{s}$, whereas rocks with interparticle or with high microporosity have velocities that can be lower by over $2500 \mathrm{~m} / \mathrm{s}$ (Figures 6 and 7). The differences of velocity caused by the different pore type persist with increasing pressure. Rocks with moldic or intraframe porosity generally have a high starting velocity and small increases with increasing pressure. In rocks with microporosity and intercrystalline porosity initial velocity is low and increases with increasing pressure without reaching velocities of the high-rigid counterparts with the same porosity (Figure 8). The observed complicated porosity-velocity relation that causes a similar porosity-impedance pattern implies that an impedance contrast between two layers can occur even without a porosity change, caused only by the different porosity types. In contrast, two layers with different porosity amounts can have very similar velocities and may have no impedance contrast between them.

Less important factors for velocity. In siliciclastic rocks mineralogy has a major influence on the sonic velocity; in carbonates this factor is much less important. For example, the amount of dolomite has little correlation with velocity, although there is a small contrast of $V_{P}$ in the two dominant carbonate minerals calcite $(6500 \mathrm{~m} / \mathrm{s})$ and dolomite $(7300$ $\mathrm{m} / \mathrm{s}$ ). Completely dolomitized rocks can be the fastest but also the slowest samples of a data set.

The velocity depends more on the type of dolomite than the amount. For example, fabric destructive sucrosic dolomitization produces an intercrystalline pore type and a resultant low velocity (Figure 7). In contrast, fabric preserving, crystalline mimetic dolomitization results in densely cemented rock with very high velocities. Many carbonates contain a small amount of insolubles such as clay minerals, organic matter, and windblown quartz. As long as these insolubles are less than $5 \%$ of the rock weight they have little influence. Once a threshold of 5\% is reached the insolubles continuously reduce the velocity in carbonates.

Taking advantage of the pore type. As shown above, pore geometry is a crucial factor in controlling acoustic properties in carbonates with the consequence that the velocity scattering at equal porosities can be attributed to the occurrence of a dominant pore type. This knowledge of the complicated pore type/porosity-velocity correlation in carbonates can be used to exploit porosity-velocity data sets to predict the trend of pore types, their associated diagenesis, and permeability trends. The "velocity deviation $\log$," which calculates the departure of the sonic velocity from the velocity predicted by the time average equation for the same porosity and lithology is used to quantify the scattering of velocities at equal porosity (Anselmetti and Eberli, 1999).

This methodology is similar to the method used by Schlumberger's SPI to calculate secondary porosity, which converts the sonic log to porosity by applying the time average equation. However, we decided to concentrate on the acoustic perspective and quantify the velocity deviations rather than the porosity deviations. The advantage of this approach is that the velocity quantification has the potential to link the seismic data to petrophysical data. Thus, a 


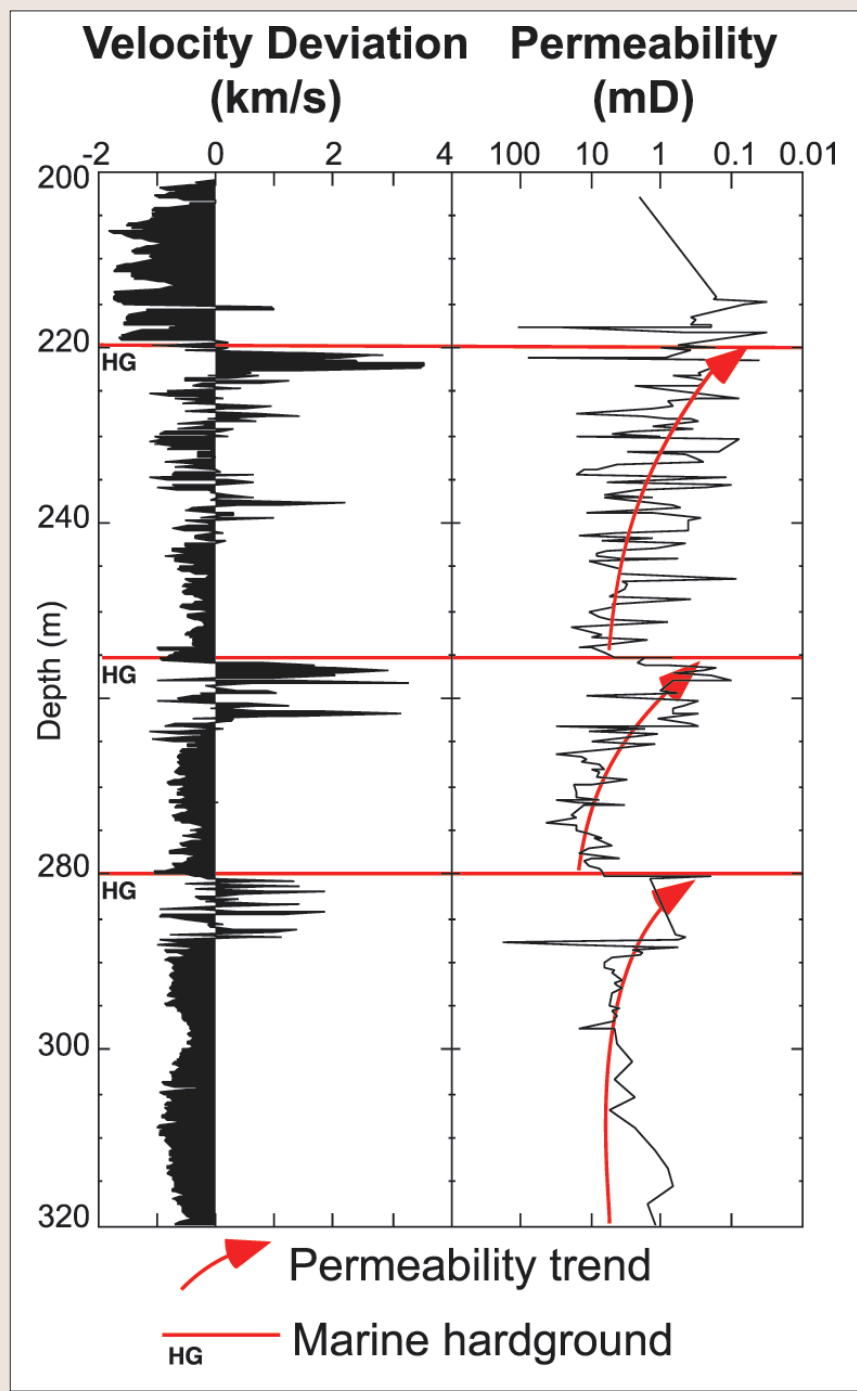

Figure 10. Correlation of velocity deviation log and permeability data in a 120-m interval of a hole from top of Great Bahama Bank. The interval consists of fine-grained slope sediments that are intercalated by three marine hardgrounds. Velocity increases upcore and decreases abruptly across the hardground surfaces. Permeability shows an inverse trend with decreasing values upcore and abrupt increases across the hardgrounds. The good inverse correlation between velocity deviation and permeability indicates a significant link between velocity deviation and trends in permeability.

sample with positive deviation has a velocity that is higher than predicted by the time average equation, whereas a negative deviation has a velocity that is lower than the porosity value would suggest (Figure 9). Rocks with high porosity but high frame flexibility produce positive deviations. In these rocks constructive cementation forms a stiff frame around porosity as is present in moldic rocks. Rocks with a low frame flexibility like sucrosic dolomite with intercrystalline porosity or fine-crystalline microporosity cause negative deviations.

The velocity deviation log applies the porosity-velocity relation obtained from discrete samples in the laboratory to the continuous record of downhole wireline logs. The advantage of using logs is that whole packages that represent specific pore types can be displayed in a continuous, synthetic downhole log. Consequently, depositional and diagenetic zones can be interpreted that would not be recognizable by solely analyzing the porosity or sonic logs. The velocity deviation $\log$ is calculated by first converting porosity-log data to a synthetic velocity log using the time average equation. The difference between the real sonic log and the synthetic sonic $\log$ can then be plotted as a velocity-deviation log. These deviations are the result of the variability of the velocity at certain porosity and, thus, reflect the different rock-physical signature of the different pore types. Based on the laboratory analysis, positive deviations indicate relatively high velocities in regard to porosity. They are caused mainly by porosity that is integrated in a framelike fabric of the rock, such as intrafossil or moldic porosity. These pore types also indicate intense diagenetic alteration with dissolution and precipitation. The deviation $\log$, consequently, can be used not only to detect the rock-frame flexibility but also the associated diagenesis. Furthermore, a connection can be made to permeability. Permeability, like velocity, in carbonates is strongly affected by the pore type and the connectivity of the pores and less by the total porosity. Because the sonic deviation log is a direct indication of the pore type, it can also be interpreted as a measure of permeability. For example, positive deviations indicate zones of low permeability because they occur in zones where cementation processes have isolated pores within a dense, cemented rock. Zones with small deviations follow the predictions made by the time average equation. These zones are dominated by either microporosity, interparticle and intercrystalline pores in fine-grained rocks. These pore types are typical for rocks with little diagenesis and have well-connected pore space. Consequently, permeability is generally high in these zones, with the exception in zones where microporosity is abundant, which results in low permeability. Zones with negative deviations should not occur, based on the empirical concept of the time average. However, several factors result in negative deviations in a borehole such as caving and irregularities in the borehole wall, intense fracturing, and free gas. In our laboratory experiments, high porosity rocks with intercrystalline and interparticle porosity also display a negative deviation. Thus, these zones are usually of high permeability.

Figure 10 illustrates the correlation of the velocity deviation $\log$ with permeability on a core from the subsurface of Great Bahama Bank. In this hole the velocity deviation log was calculated from the density and sonic logs, and the permeability was measured with a minipermeameter directly on the split core at short intervals ranging from 3-0.3 m. Lithologically the core consists of fine-grained periplatform sediments that were deposited on the upper slope during the late Pliocene. The interval displayed in Figure 10 is characterized by successions of peloidal packstone and grainstone that are intercalated by intervals of strong cementation and three marine hardgrounds. The interval shows an inverse correlation between velocity deviation and permeability. The marine hardgrounds are characterized by strong positive velocity deviations. Above the hardgrounds, velocity deviations abruptly decrease to small or even negative values and gradually increase toward the next higher hardground. The permeability trend follows this pattern with an upcore decrease in average permeability and an abrupt increase of permeability across the hardgrounds. The permeability values in the hardgrounds are less than a $1 \mathrm{md}$, whole the intercalated zones have permeability values of 1-100 md. The negative correlation between velocity deviation and permeability shows that sonic velocity and permeability are controlled by similar parameters, in particular the pore type. The sonic deviation $\log$ can be interpreted to predict trends in diagenesis, resultant pore type and permeability without cores. It is, however, a qualitative assessment and further theoretical analyses are needed to quantitatively relate velocity deviation and permeability. 
Table 1. Important points for velocity in carbonates

Despite their limited mineralogy, pure carbonates can have a wide range of sonic velocity; $V_{p}$ ranges between 1700 and $6600 \mathrm{~m} / \mathrm{s}, \mathrm{V}_{\mathrm{S}}$ between 600 and $3500 \mathrm{~m} / \mathrm{s}$.

Porosity and pore types are the main parameters that control velocity, whereby variations in pore type is the main reason for variable velocity at a given porosity.

Initial lithology and diagenetic alterations control together the porosity- and the velocity-evolution from time of deposition through the different burial stages. Each diagenetic process changes velocity and acoustic impedance in a characteristic way.

Unlike in siliciclastic sediments, $V_{P}$ and $V_{S}$ in our carbonate samples show little correlation with depth or age. Compared to diagenesis, compaction alone has less effect on velocity.

Variable velocity at equal porosity induces a large uncertainty in seismic inversion and for calculations of porosity volumes from seismic data.

Dolomite content is not a criterion for a high or a low velocity.

Velocity predictions from correlations like "Gardner's equation" or "time-average equation" are in general too low and thus not applicable to carbonates.

Insolubles (mainly clay) decrease velocity in carbonates; fast velocities (>4000 m/s) are only reached if the clay content is below $5 \%$.

Conclusions and implications. Laboratory measurements on discrete carbonate samples reveal that in carbonate sediments the original composition and the amount of mud versus grain are important in determining sonic velocity (Table 1). In youngest carbonate rocks, cements dramatically change the elastic behavior of the rocks but the type of cement rather than the amount determines the degree of rigidity and thus velocity. In older carbonate rocks, the sonic velocity is not only a function of total porosity but also of the predominant pore type. There is a general inverse porosity-velocity correlation but significant deviations occur from this relationship for certain pore types. Frame-forming pore types such as moldic and intraframe porosity, result in significantly higher velocity values than do pore types that are not embedded in a frame such as intercrystalline and interparticle pores. The complicated porosity-velocity relationship can be exploited in porosity and velocity logging data to produce continuous, synthetic logs of the positive or negative deviations that give indications about the diagenetic and permeability trends in a well. The scattering in a porosity-velocity diagram, however, has negative implications for seismic inversion and AVO analyses in carbonates. The scattering produces an uncertainty in seismic inversion that most current inversion techniques are not able to reduce. If a single line from a theoretical equation or a best-fit line through the data set is used for inversion, all the velocity above the line will underestimate porosity and reserves while all the data points below will overestimate porosity and reserves. Similarly, variations in pore type can cause variations in the amplitude with offset that might be more pronounced than variations in saturation or bed thickness. New theoretical approaches are needed that will show the physical relationship between pore types, the rigidity, and the elastic behavior to reduce the uncertainties in both seismic inversion and AVO analysis.

Suggested reading. "Controls on sonic velocity in carbonates" by Anselmetti and Eberli (Pure and Applied Geophysics, 1993). "Sonic velocity in carbonate sediments and rocks," by Anselmetti and Eberli in Carbonate Seismology, (SEG, 1997). "The velocity-deviation log: A tool to predict pore type and permeability trends in carbonate drill holes from sonic and porosity or density logs" by Anselmetti and Eberli (AAPG Bulletin, 1999). "Rock-fabric/petrophysical classification of carbonate pore space for reservoir characterization" by Lucia (AAPG Bulletin, 1995). "Acoustic properties of carbonate rocks: Use in quantitative interpretation of sonic and seismic measurements" by Marion and Jizba in Carbonate Seismology. "Compressional velocity and porosity in sand-clay mixtures" by Marion et al. (GEOPHYSICS, 1992). "The relationship between acoustic properties and the petrographic character of carbonate rocks" by Rafavich et al. (GEOPHYSICS, 1984). "Seismic velocities in carbonate rocks" by Wang et al. (Journal of Canadian Petroleum Technology, 1991). "Seismic properties of carbonate rocks" by Wang in Carbonate Seismology, (SEG, 1997). TLE

Corresponding author: geberli@rsmas.miami.edu 